\section{Reduction and Coupling Reactions of Carbonyl Compounds Using Samarium Metal in Aqueous Media}

\author{
Sanjay Talukdar and J im-Min Fang*
}

Department of Chemistry, National Taiwan University, Taipe, Taiwan 106, Republic of China

\section{jmfang@mail.ch.ntu.edu.tw}

Received September 14, 2000

Direct use of metallic Sm as a reducing agent in organic transformations has drawn chemists' attention. ${ }^{1}$ Such reactions are generally performed in THF. For example, alkyl iodides are reduced to alkanes by $\mathrm{Sm}$ in THF . ${ }^{2 a}$ Barbier reaction of 2-(3-iodopropyl)cycl oheptanone with Sm in THF occurs intramolecularly to give a bicyclic alcohol. ${ }^{2 \mathrm{~b}}$ lodomethylations of carbonyl compounds are achieved by treatment with $\mathrm{Sm}$ and $\mathrm{CH}_{2} \mathrm{I}_{2}$ in THF. ${ }^{2 \mathrm{C}}$

Since water is an environmentally benign medium, we wish to explore further the reactions of carbonyl compounds with $\mathrm{Sm}$ in aqueous media. ${ }^{3} \mathrm{Sm}$ is quite stable in water even though it has a high reduction potential $\left(\mathrm{Sm}^{3+} / \mathrm{Sm}=-2.41 \mathrm{~V}\right){ }^{4}$

There are several methods 2,5 for activation of Sm metal such as amalgamation using $\mathrm{I}_{2}, \mathrm{HCl}$, and alkyl halides. Cyclopropanations of esters, $\alpha$-halo ketones, and allylic alcohols are realized by using $\mathrm{Sm}(\mathrm{Hg}) / / \mathrm{CH}_{2} \mathrm{Cl}$ or $\mathrm{Sm} /$ $\mathrm{HgCl}_{2} / \mathrm{ICH}_{2} \mathrm{Cl}$ in THF .2d,e Sm with a catalytic amount of $\mathrm{I}_{2}$ in THF is used in the reductive coupling reactions of $\mathrm{N}$-alkylideneanilines, giving vicinal diamines. ${ }^{2 f}$ Deoxygenative coupling reactions of benzamides, giving 1,2diaminostilbenes, are carried out by using Sm with a catalytic amount of $\mathrm{Sml}_{2}$ in THF ${ }^{2 g} \mathrm{~A}$ minute amount of

* To whom correspondence should be addressed. Fax: (886-2)2363-6359.

(1) (a) Kagan, H. B.; Namy, J. L. Tetrahedron 1986, 42, 6573. (b) Molander, G. A.; Harris, C. R. In Encyclopedia of Reagents for Organic Synthesis; Paquette, L. A., Ed.; Wiley: Chichester, 1995; Vol. 6, p 4425.

(2) (a) Ogawa, A.; Nanke, T.; Takami, N.; Sumino, Y.; Ryu, I.; Sonoda, N. Chem. Lett. 1994, 379. (b) Molander, G. A.; Etter, J. B. J Org. Chem. 1986, 51, 1778. (c) I mamoto, T.; Takeyam, T.; Koto, H. Tetrahedron Lett. 1986, 27, 3243. (d) Imamoto, T.; Kamiya, Y. Hatajima, T.; Takahashi, H. Tetrahedron Lett. 1989, 38, 5149. (e) Molander, G. A.; Etter, J . B. J . Org. Chem. 1987, 52, 3942. (f) Yanada, R.; Negoro, N.; Okaniwa, M.; Miwa, Y.; Taga, T.; Yanada, K.; Fujita, T. Synlett 1999, 537. (g) Ogawa, A.; Takami, N.; Sekiguchi, M.; Ryu, I.; Kambe, N.; Sonoda, N. J. Am. Chem. Soc. 1992, 114, 8729.

(3) $\mathrm{Zn}$, In and Sn metals are often operative in aqueous media. For reviews, see: (a) Li, C. J .; Chan, T. H. Organic Reactions in Aqueous Media; Wiley: New York, 1997. (b) Chan, T. H.; Li, C. J .; Lee, M. C.; Wei, Z. Y. Can. J . Chem. 1994, 72, 1181. (c) Li, C. J . Tetrahedron 1996, 52, 5643. (d) Lubineau, A.; Auge, J .; Queneau, Y. Synthesis 1994, 741.

(4) For the reduction potential and stability of Sm in water. See: (a) Moeller, T. In Comprehensive Inorganic Chemistry; Bailar, J . C. Emeleus, H. J ., Nyholm, R., Trotman-Dickenson, A. F., Eds.; Pergamon Press: Oxford, 1973; Vol. 4, p 5. (b) Latimer, W. M. The Oxidation States of the Elements and Their Potentials in Aqueous Solution, 2nd ed.; Prentice Hall Inc.: Englewood Cliffs, NJ , 1952; p 340.

(5) (a) Wang, L.; Zhang, Y. Tetrahedron 1998, 54, 11129. (b) Banik B. K.; Mukhopadhyay, C.; Venkatraman, M. S.; Becker, F. F. Tetrahedron Lett. 1998, 39, 7243. (c) Yanada, R.; Negora. N.; Yanada, K.; Fujita, T. Tetrahedron Lett. 1997, 38, 3271. (d) Yanada, R.; Bessho, K.; Yanada, K. Chem. Lett. 1994, 1279. (e) Komachi, Y.; Kudo, T. Chem Pharm. Bull. 1994, 42, 402. (f) Komachi, Y.; Kudo, T. Chem. Pharm. Bull. 1995, 43, 1422. (g) Ghatak, A.; Becker, F. F.; Banik, B. K. Tetrahedron Lett. 2000, 41, 3793. water is found to accelerate the pinacolic coupling reactions of aromatic carbonyl compounds mediated by $\mathrm{Sm} /$ $\mathrm{Me}_{3} \mathrm{SiCl}$ in THF.5a Reductions of nitrobenzene, ${ }^{5 \mathrm{~b}} 1,2-$ dibromoalkanes, ${ }^{5 c, d}$ benzoic acid derivatives, 5 e and pyridines ${ }^{5 f}$ have been realized by using $\mathrm{Sm} / \mathrm{I}_{2}$ or $\mathrm{Sm} / \mathrm{HCl}_{\mathrm{aq}}$ in $\mathrm{MeOH}$. Pinacolic coupling reactions of aromatic ketones have been achieved by using Sm with alkyl halides in $\mathrm{MeOH} .{ }^{59}$ The expected Barbier-type addition products are not found.5g

Our study was initiated by examining the reactivity of 4-bromobenzal dehyde (1b) with Sm in aqueous media (Table 1). The Sm ingot was abraded (by a file) to give shining powders for the present study. Treatment of $\mathbf{~} \mathbf{l b}$ with $\mathrm{Sm}$ (1.2 molar proportions) in $\mathrm{H}_{2} \mathrm{O} / \mathrm{THF}(5: 1)$ for 72 $\mathrm{h}$ afforded very low yields of pinacol $\mathbf{2} \mathbf{b}(3 \%)$ and alcohol 3b $(2 \%)$ accompanied by a $95 \%$ recovery of $\mathbf{1 b}$. The residual Sm had tarnished by the end of the reaction. The reaction was not significantly improved by sonication or by using an excessive amount of Sm (entries 2 and 3, Table 1).

We thus searched for appropriate activators to enhance the reactivity of $\mathrm{Sm}$ in aqueous media. ${ }^{2,5,6}$ I ndeed, treatment of $\mathbf{1 b}$ with $\mathrm{Sm}$ (3 molar proportions) in the presence of $\mathrm{HgCl}_{2}$ (1.5 molar proportions) gave much higher yields of pinacol $\mathbf{2 b}(48 \%)$ and alcohol $\mathbf{3 b}(38 \%)$ in $\mathrm{H}_{2} \mathrm{O} / \mathrm{THF}$ media (entry 4, Table 1). Iodine was also an effective activator of Sm (entries 6-8). ${ }^{2 f}$ By using Sm (3 molar proportions) with $I_{2}$ (0.75 molar proportions), $\mathbf{1 b}$ was completely converted in $16 \mathrm{~h}$ to give equal amounts of $\mathbf{2} \mathbf{b}$ and $\mathbf{3 b}$. Preferable formation of pinacol $\mathbf{2} \mathbf{b}$ over alcohol $\mathbf{3 b}$ was realized by using $\mathrm{Sm}$ in saturated $\mathrm{NH}_{4-}$ $\mathrm{Cl} / \mathrm{THF}(5: 1)$ or with $\mathrm{FeCl}_{3}$ activation (entries 9 and 10, Table 1). The bromine atom of $\mathbf{1 b}$ was retained in all of these reaction conditions.

After a comprehensive survey on the optimization of reaction conditions, we found that the reaction in aqueous $\mathrm{HCl}$ solution $(2 \mathrm{M})^{5 \mathrm{~d}-\mathrm{f}}$ produced an $88 \%$ yield of pinacol $\mathbf{2 b}$ in a chemoselective manner (entry 12, Table 1). Thus, Sm (3 molar proportions) was added in several portions to a suspension of $\mathbf{1 b}(1 \mathrm{mmol})$ in $2 \mathrm{M} \mathrm{HCl} / \mathrm{THF}(5: 1)$ over a period of $1 \mathrm{~h}$ at room temperature. Upon addition of Sm powders, a transient purple color and hydrogen evolution were observed. The reaction mixture was continuously stirred without rigorous exclusion of oxygen. It required $32 \mathrm{~h}$ for the consumption of 4-bromobenzaldehyde as shown by TLC analyses. The media became transparent at the end of the reaction, and no residue of $\mathrm{Sm}$ particles remained. The reaction did not proceed to completion if the amount of Sm was less than $1.2 \mathrm{molar}$ proportions. A considerable portion of starting material 1b was recovered if the reaction was conducted by addition of aqueous $\mathrm{HCl}$ solution to the suspension of $\mathbf{1 b}$ and $\mathrm{Sm}$ in THF (entry 13, Table 1). The reaction in aqueous $\mathrm{HBr}$ was less chemoselective (entry 14, Table

(6) General methods for activation of metals, see: (a) Cintas, P., Activated Metals in Organic Synthesis; CRC Press: Boca Raton, 1993. (b) Furstner, A. Active Metals - Preparation, Characterization and Application; VCH: Weinheim, 1996. For activation of $\mathrm{Sm}$ by $\mathrm{ICH}_{2-}$ $\mathrm{CH}_{2} \mathrm{I}, \mathrm{I}_{2}, \mathrm{Hgl}_{2}$, and $\mathrm{Et}_{2} \mathrm{All}$ to generate $\mathrm{Sml}_{2}$, see: (c) Girard, P.; Namy, J . L.; Kagan, H. B. J . Am. Chem. Soc. 1980, 102, 2693. (Sm/l $\left.\mathrm{CH}_{2} \mathrm{CH}_{2} \mathrm{l}\right)$. (d) I mamoto, T.; Ono, M. Chem. Lett. 1987, 501. $\left(\mathrm{Sm} / \mathrm{I}_{2}\right)$. (e) Deacon, G. B.; Forsyth, C. M. Chem. Lett. 1989, 837. (Sm/Hgl 2 ). (f) Nishiyama, Y.; Shinomiya, E.; Kimura, S.; Itoh, K.; Sonoda, N. Tetrahedron Lett. 1998, 39, 3705 . 
Table 1. Reactions of 4-Bromobenzaldehyde (1b, $1 \mathrm{mmol})$ with Samarium in Various Conditions ${ }^{\mathrm{a}}$

\begin{tabular}{|c|c|c|c|c|c|c|}
\hline entry & $\begin{array}{c}\mathrm{Sm} \\
(\mathrm{mmol})\end{array}$ & $\begin{array}{l}\text { reaction medium, } \\
\text { additive (mmol) }\end{array}$ & $\begin{array}{l}\text { reaction } \\
\text { time }(\mathrm{h})\end{array}$ & $\begin{array}{c}\text { pinacol } \mathbf{2 b}^{b} \\
\text { (yield, \%) } \\
\text { (dl/meso) }\end{array}$ & $\begin{array}{l}\text { alcohol } \mathbf{3 b}^{\mathrm{b}} \\
\text { (yield, \%) }\end{array}$ & $\begin{array}{c}\text { recovery of } \\
\mathbf{1 b}^{\mathrm{b}}(\%)\end{array}$ \\
\hline 1 & 1.2 & $\mathrm{H}_{2} \mathrm{O} / \mathrm{THF}^{\mathrm{c}}$ & 72 & $3(54: 46)$ & 2 & 95 \\
\hline $2^{d}$ & 1.2 & $\mathrm{H}_{2} \mathrm{O} / \mathrm{THFC}$ & 32 & $6(50: 50)$ & $<\overline{2}$ & 92 \\
\hline 3 & 3.0 & $\mathrm{H}_{2} \mathrm{O} / \mathrm{THF}^{\mathrm{c}}$ & 48 & $3(55: 45)$ & 2 & 95 \\
\hline 4 & 1.2 & $\mathrm{H}_{2} \mathrm{O} / \mathrm{THF}{ }^{\mathrm{c}} \mathrm{HgCl}_{2}$ (0.6) & 48 & $8(61: 39)$ & 4 & 88 \\
\hline 5 & 3.0 & $\mathrm{H}_{2} \mathrm{O} / \mathrm{THF}, \mathrm{c} \mathrm{HgCl}_{2}$ (1.5) & 36 & $48(38: 62)$ & 38 & 14 \\
\hline 6 & 1.2 & $\mathrm{H}_{2} \mathrm{O} / \mathrm{THF}, \mathrm{Cl}_{2}(0.6)$ & 32 & $22(50: 50)$ & 19 & 59 \\
\hline 7 & 3.0 & $\mathrm{H}_{2} \mathrm{O} / \mathrm{THF}, \mathrm{Cl}_{2}(0.75)$ & 16 & $50(40: 60)$ & 50 & 0 \\
\hline 8 & 3.0 & $\mathrm{H}_{2} \mathrm{O} / \mathrm{THF}^{\prime}, \mathrm{Cl}_{2}(1.5)$ & 36 & $42(45: 55)$ & 41 & 17 \\
\hline 9 & 3.0 & $\mathrm{H}_{2} \mathrm{O} / \mathrm{THF},{ }^{\circ} \mathrm{FeCl}_{3}(1.5)$ & 36 & 71 (48:52) & 12 & 0 \\
\hline 10 & 3.0 & satd. $\mathrm{NH}_{4} \mathrm{Cl} / \mathrm{THF} \mathrm{F}^{\mathrm{C}}$ & 36 & $66(50: 50)$ & 20 & 14 \\
\hline 11 & 1.2 & $2 \mathrm{M} \mathrm{HCl} / \mathrm{THF}^{\mathrm{C}}$ & 32 & $53(33: 66)$ & 4 & 42 \\
\hline 12 & 3.0 & $2 \mathrm{M} \mathrm{HCl} / \mathrm{THF}^{\mathrm{c}}$ & 32 & $88(36: 64)^{e}$ & 5 & 0 \\
\hline $13^{f}$ & 3.0 & $2 \mathrm{M} \mathrm{HCl} / \mathrm{THFC}^{\circ}$ & 32 & $40(49: 51)$ & 4 & 56 \\
\hline 14 & 3.0 & $2 \mathrm{M} \mathrm{HBr} / \mathrm{THF}^{\mathrm{C}}$ & 32 & $77(47: 53)^{e}$ & 14 & 0 \\
\hline $15^{9}$ & 3.0 & $2 \mathrm{M} \mathrm{HI} / \mathrm{THF}^{\mathrm{C}}$ & 32 & $<2$ & & 0 \\
\hline
\end{tabular}

a The reaction was conducted at room temperature by addition of Sm in several portions over a period of $1 \mathrm{~h}$ to the suspension of $\mathbf{1 b}$ in the indicated medium. ${ }^{b}$ Except for entries 12 and $\mathbf{1 4}$, the data for $\mathbf{1 b}, \mathbf{2} \mathbf{b}$, and $\mathbf{3 b}$ were calculated on the basis of ${ }^{1} \mathrm{H}$ NMR spectral analysis of the crude product mixture. ' The ratio of water (or aqueous solution) to THF is 5:1 (v/v). ${ }^{d}$ Irradiation in an ultrasonic bath (35 $\mathrm{kHz}$ ). e The isolated yields are reported. ${ }^{\mathrm{f}} \mathrm{The} \mathrm{HCl}$ solution was added in several portions to the suspension of Sm and 4-bromobenzal dehyde in THF. ${ }^{g}$ The reaction gave many unidentified products.

Table 2. Reactions of Aromatic Carbonyls (1 mmol) with Samarium (3 mmol) in $2 \mathrm{M} \mathrm{HCl} / \mathrm{THF}(5: 1)$ at $20^{\circ} \mathrm{C}$ (1-3 days)

\begin{tabular}{|c|c|c|c|}
\hline entry & substrate & $\begin{array}{c}\text { pinacola (yield, \%) }_{(\mathrm{dl} / \text { meso) }} \\
\text { (a) }\end{array}$ & $\begin{array}{l}\text { alcohola }^{\text {a }} \\
\text { (yield, \%) }\end{array}$ \\
\hline 1 & $\mathrm{PhCHO}$ (1a) & $2 a(80)(48: 52)$ & $3 a(18)$ \\
\hline 2 & $4-\mathrm{BrC}_{6} \mathrm{H}_{4} \mathrm{CHO}(\mathbf{1 b})$ & $\mathbf{2 b}(88)(36: 64)$ & $3 \mathbf{b}(5)$ \\
\hline 3 & 4- $\mathrm{PhC}_{6} \mathrm{H}_{4} \mathrm{CHO}(\mathbf{l c})$ & $2 c(75)(92: 8)$ & $3 c(5)$ \\
\hline 4 & $3-\mathrm{CF}_{3} \mathrm{C}_{6} \mathrm{H}_{4} \mathrm{CHO}$ (1d) & 2d (92) (58:42) & \\
\hline 5 & $4-\mathrm{NCC}_{6} \mathrm{H}_{4} \mathrm{CHO}(\mathbf{l e})$ & $2 e(79)(52: 48)$ & $3 e(14)$ \\
\hline 6 & $4-\mathrm{MeO}_{2} \mathrm{CC}_{6} \mathrm{H}_{4} \mathrm{CHO}$ (1f) & $2 f(46)(57: 43)^{b}$ & $3 f(2)$ \\
\hline 7 & $2-\mathrm{O}_{2} \mathrm{NC}_{6} \mathrm{H}_{4} \mathrm{CHO}(\mathbf{l g})$ & no reaction ${ }^{c}$ & \\
\hline 8 & $3-\mathrm{O}_{2} \mathrm{NC}_{6} \mathrm{H}_{4} \mathrm{CHO}$ (1h) & no reactionc & \\
\hline 9 & $4-\mathrm{MeC}_{6} \mathrm{H}_{4} \mathrm{CHO}(\mathbf{l i})$ & $2 i(83)(51: 49)$ & $3 \mathbf{i}(10)$ \\
\hline 10 & $4-\mathrm{MeOC}_{6} \mathrm{H}_{4} \mathrm{CHO}$ (1j) & 2j (84) (12:88) & $3 \mathbf{j}(2)$ \\
\hline 11 & $2-\mathrm{HOC}_{6} \mathrm{H}_{4} \mathrm{CHO}(\mathbf{l} \mathbf{k})$ & $2 \mathbf{k}(60)(56: 44)$ & $3 \mathbf{k}(16)$ \\
\hline 12 & PhCOMe (1l) & 2l (92) $(49: 51)$ & 3I (2) \\
\hline 13 & PhCOEt (1m) & $\mathbf{2 m}(85)(62: 38)$ & $3 \mathbf{m}(2)$ \\
\hline 14 & $4-\mathrm{MeOC}_{6} \mathrm{H}_{4} \mathrm{COMe}(\mathbf{l n})$ & 2n (85) $(64: 36)$ & \\
\hline 15 & $2-\mathrm{MeC}_{6} \mathrm{H}_{4} \mathrm{COMe}$ (10) & $20(90)(49: 51)$ & $30(2)$ \\
\hline 16 & 2-acetylnaphthalene (1p) & $2 p(94)(62: 38)$ & \\
\hline 17 & PhCOPh (1q) & $2 q(94)$ & \\
\hline
\end{tabular}

a The isolated yields are reported. The ratio of $\mathrm{dl}$ and meso isomers was determined by the ${ }^{1} \mathrm{H}$ NMR analysis of the crude product mixture. ${ }^{b}$ The starting material 1 ff was recovered ( $\left.~ 50 \%\right)$. c The starting materials $\mathbf{I g}$ and $\mathbf{l h}$ were recovered (>95\%).

1), whereas many unidentified products complicated the reaction in aqueous $\mathrm{HI}$ (entry 15 , Table 1 ).

The protocol using Sm (3 molar proportions) in $2 \mathrm{M}$ $\mathrm{HCl} / \mathrm{THF}$ (5:1) was applied to the pinacolic coupling reactions of other benzaldehydes and aromatic ketones (eq 1 and Table 2). In most cases, high yields of pinacols

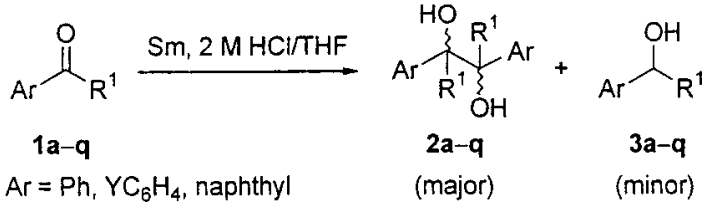

$$
\begin{aligned}
& \mathrm{R}^{1}=\mathrm{H}, \mathrm{Me}, \mathrm{Et}, \mathrm{Ph}
\end{aligned}
$$

were obtained as mixtures of $\mathrm{dl}$ and meso isomers under such reaction conditions. ${ }^{7,8}$ The pinacolic coupling reaction of benzophenone was also successfully carried out by using Sm in aqueous media to give a $94 \%$ yield of benzopinacol (entry 17, Table 2). Unimolecular reduction,
Table 3. Reactions of Aliphatic Carbonyls (1 mmol) with Samarium ( $3 \mathrm{mmol}$ ) in $2 \mathrm{M} \mathrm{HCl} / \mathrm{THF}(5: 1)$ at $20^{\circ} \mathrm{C}$ (18-28 h)

\begin{tabular}{|c|c|c|}
\hline entry & substrate & $\begin{array}{c}\text { alcohola (yield, \%) }^{\text {(cis/trans) }}\end{array}$ \\
\hline 1 & $\mathrm{CH}_{3}\left(\mathrm{CH}_{2}\right)_{7} \mathrm{CHO}$ (4a) & 5a (94) \\
\hline 2 & $\mathrm{PhCH}_{2} \mathrm{CHO}(\mathbf{4 b})$ & $5 \mathbf{b}(87)$ \\
\hline 3 & $\mathrm{Ph}\left(\mathrm{CH}_{2}\right)_{2} \mathrm{CHO}(\mathbf{4 c})$ & 5c (95) \\
\hline 4 & $\mathrm{PhCH}\left(\mathrm{CH}_{3}\right) \mathrm{CHO}(\mathbf{4 d})$ & 5d (100) \\
\hline 5 & $\mathrm{PhCH}_{2} \mathrm{COMe}(4 \mathrm{e})$ & $5 \mathbf{e}(95)$ \\
\hline 6 & 2-adamantanone (4f) & $5 f(94)$ \\
\hline 7 & $\mathrm{MeCOCH}_{2} \mathrm{COOBu}^{\mathrm{t}}(\mathbf{4 g})$ & $5 \mathbf{g}(97)$ \\
\hline 8 & 2-methylcyclohexanone (4h) & $5 \widehat{h}(89)(50: 50)$ \\
\hline 9 & 2-tert-butylcyclohexanone (4i) & $5 i(85)(60: 40)$ \\
\hline 10 & 2-methoxycyclohexanone (4j) & 5j (87) $(80: 20)$ \\
\hline 11 & 4-tert-butylcyclohexanone (4k) & $5 \mathbf{k}(90)(15: 85)$ \\
\hline
\end{tabular}

a The isolated yields are reported. The ratio of cis and trans isomers was determined by the ${ }^{1} \mathrm{H}$ NMR analysis of the crude product mixture. No pinacols were detected in the crude product mixtures according to the ${ }^{1} \mathrm{H}$ and ${ }^{13} \mathrm{C}$ NMR analyses.

giving alcoholic products, was either a minor pathway or did not occur. Benzaldehydes bearing trifluoromethyl, cyano, or hydroxyl groups proceeded similarly to give pinacols $\mathbf{2} \mathbf{d}, \mathbf{2 e}$, and $\mathbf{2} \mathbf{k}$ as the major products, respectively (entries 4, 5, and 11, Table 2). The reaction of $\mathbf{1 f}$ bearing a methoxycarbonyl group was incomplete after $36 \mathrm{~h}$ (entry 6, Table 2), and nitrobenzal dehydes $\mathbf{1 g}$ and

(7) The real nature of reducing species in the $\mathrm{Sm} / \mathrm{HCl} / \mathrm{H}_{2} \mathrm{O} / \mathrm{THF}$ system was unclear. An initial reaction of $\mathrm{Sm}$ with aqueous $\mathrm{HCl}$ might generate $\mathrm{SmCl}_{3}$, which might undergo disproportionation with excess of Sm to low-valent samarium species $\left(\mathrm{SmCl}, \mathrm{SmCl}_{2}\right.$ or the corresponding hydroxides) as the reducing agent. See: (a) Moeller, T. In Comprehensive Inorganic Chemistry; Bailar, J. C., Emeleus, H. J ., Nyholm, R., Trotman-Dickenson, A. F.. Eds.; Pergamon Press: Oxford, Vol. 7, 1973; p 3599 and 3615. (b) Enemaerke, R. J .; Daasbjerg, K. Skrydstrup, T. Chem Commun. 1999, 343. (c) Fuchs, J . R.; Mitchall, M. L.; Shabangi, M.; Flowers, R. A., II. Tetrahedron Lett. 1997, 38, 8157. $\mathrm{SmCl}_{3}$-catalyzed electrolyses of aromatic al dehydes and ketones in DMF or NMP also give pinacols. See: (d) Leonard, E.; Dunbach, E.; Pericho, J. Chem. Commun. 1989, 276.

(8) Pinacolic coupling of aromatic carbonyl compounds has been achieved by using $\mathrm{Zn}$ in aqueous $\mathrm{NaOH}$ solution. See: (a) Tsukinoki, T.; Kawaji, T.; Hashimoto, I.; Mataka, S.; Tashiro, M. Chem. Lett. 1997, 235. A pinacolic coupling reaction between acetone and 2-cyclohexenone has been carried out by using $\mathrm{Zn}(\mathrm{Cu})$ with sonication in water. See: (b) Delair, P.; Luche, J .-L. Chem. Commun. 1989, 398. Using Al with fluoride salts in aqueous media provides an efficient method for pinacolic coupling reactions of aromatic carbonyl compounds. See: (c) Li, L.-H.; Chan, T. H. Org. Lett. 2000, 2, 1129. 
Table 4. Comparison of the Reactions of Carbonyl Compounds Using Sm Metal in Various Conditions: (i) Sm/2 M $\mathrm{HCl} / \mathrm{THF}$, (ii) Sm(Hg)/THF, (iii) Sm/Mes $\mathrm{SiCl} / \mathrm{H}_{2} \mathrm{O}$ (trace), (iv) Sm/l $/ \mathrm{MeOH}$, (v) Sm/l $/ \mathrm{Ti}(\mathrm{Oi}-\mathrm{Pr}$ ) $/ \mathrm{MeOH}$, (vi) Sm/Allyl Bromide/MeOH, (vii) Sm/THF/HMPA

\begin{tabular}{|c|c|c|c|c|c|}
\hline \multirow[b]{2}{*}{ substrates } & \multirow{2}{*}{$\begin{array}{l}\text { reaction } \\
\text { conditions }\end{array}$} & \multirow{2}{*}{$\begin{array}{c}\text { no. of } \\
\text { examples }\end{array}$} & \multicolumn{2}{|c|}{ products (yield, \%) } & \multirow[b]{2}{*}{ ref } \\
\hline & & & pinacols & alcohols & \\
\hline \multirow[t]{5}{*}{ benzaldehydes } & $\mathrm{i}$ & 7 & $75-92$ & $0-18$ & this study \\
\hline & ii & 7 & $65-82$ & & $10 a$ \\
\hline & iii & 5 & $78-83$ & & $5 a$ \\
\hline & iv & 2 & 71 and 91 & 22 and 0 & $5 c$ \\
\hline & $\mathrm{v}$ & 8 & $90-98$ & $0-8$ & $5 c$ \\
\hline \multirow{3}{*}{$\begin{array}{l}\mathrm{PhCH}(\mathrm{OMe})_{2} \\
2-\mathrm{HOC}_{6} \mathrm{H}_{4} \mathrm{CHO}\end{array}$} & $\mathrm{i}$ & 1 & 98 & & this study \\
\hline & i & 1 & 60 & 16 & this study \\
\hline & v & 1 & 10 & 88 & $5 c$ \\
\hline \multirow{6}{*}{ acetophenones } & i & 3 & $85-92$ & & this study \\
\hline & ii & 2 & $71-74$ & & $10 a$ \\
\hline & iii & 1 & 80 & & $5 a$ \\
\hline & iv & 1 & 71 & 24 & $5 c$ \\
\hline & $\mathrm{v}$ & 1 & 5 & 7 & $5 c$ \\
\hline & vi & 5 & $50-69$ & $0-11$ & $5 g$ \\
\hline \multirow[t]{4}{*}{ PhCOPh } & i & 1 & 94 & & this study \\
\hline & $\mathrm{v}$ & 1 & & 18 & $5 c$ \\
\hline & vi & 1 & 59 & & $5 g$ \\
\hline & vii & 1 & 62 & 31 & 10b \\
\hline \multirow[t]{3}{*}{ aliphatic aldehydes } & i & 4 & & $87-100$ & this study \\
\hline & iii & 1 & no reaction & & $5 a$ \\
\hline & iv & 2 & & $94-95$ & $5 c$ \\
\hline \multirow[t]{2}{*}{ aliphatic ketones } & i & 6 & & $87-97$ & this study \\
\hline & iii & 1 & no reaction & & $5 a$ \\
\hline
\end{tabular}

Ih were inert under such reaction conditions (entries 7 and 8, Table 2).

Unlike aromatic carbonyl compounds, the reactions of aliphatic aldehydes and ketones (4a-k) using $\mathrm{Sm}$ (3 molar proportions) in $2 \mathrm{M} \mathrm{HCl} / \mathrm{THF}$ (5:1) gave exclusively the corresponding alcohols $\mathbf{5 a}-\mathbf{k}$ in very high yields (Table 3). ${ }^{9}$ No reductive coupling products were formed

$$
\begin{aligned}
& \mathrm{R}_{\mathrm{R}^{3}} \frac{\mathrm{Sm}, 2 \mathrm{M} \mathrm{HCl} / \mathrm{THF}}{85-100 \% \text { yields }} \\
& \begin{array}{c}
\text { (aliphatic, acyclic and cyclic } \\
\text { aldehydes and ketones) }
\end{array}
\end{aligned}
$$

as shown by the ${ }^{1 \mathrm{H}} \mathrm{NMR}$ analyses. The reduction of tertbutyl acetoacetate gave a 97\% yield of tert-butyl 3-hydroxybutanoate without hydrolysis or reduction of the ester group (entry 7, Table 3). The reduction of 2-methylcyclohexanone gave 2-methylcyclohexanol as a mixture of cis and trans isomers in equal amounts (entry 8, Table $3)$. In the reductions of 2-tert-butylcyclohexanone and 2-methoxycyclohexanone, the ratios of cis alcohol products $\mathbf{5 i}$ and $\mathbf{5 j}$ increased to $60 \%$ and $80 \%$, respectively (entries 9 and 10, Table 3). The increase of stereoselectivity could be attributable to the steric effect of the neighboring t-Bu group and the chelation effect of methoxy group. However, the reduction of 4-tert-butylcyclohexanone afforded predominantly the thermodynamically stable trans isomer with the hydroxyl group on the equatorial position (entry 11, Table 3).

We can make a comparison of our current study with

(9) (a) Huffman, J. W. In Comprehensive Organic Synthesis; Trost, B. M., Fleming, I., Eds.; Pergamon Press: Oxford, 1991; Vol. 8, Chapter 1.4. Aldehydes and aromatic ketones, but not aliphatic ketones, are reduced to alcohols by using $\mathrm{Fe} / \mathrm{HOAc}$ or $\mathrm{Zn}$ in alkaline solution. Aliphatic ketones are reduced by $\mathrm{Na}$ in $\mathrm{EtOH}$ or $\mathrm{Na}(\mathrm{Hg})$ in water under careful operation. The amal gams of $\mathrm{Zn}, \mathrm{Mg}, \mathrm{Ni}, \mathrm{Cu}, \mathrm{Sn}$ or $\mathrm{Pb}$ in aqueous THF are not effective in reductions of cyclohexanones. (b) According to ref $8 \mathrm{~b}$, cyclohexanecarbaldehyde is reduced by $\mathrm{Al} / \mathrm{KF}$ in aqueous medium to give $10 \%$ of cyclohexylmethanol. However, cyclohexanone and 2-hexanone cannot be reduced by using $\mathrm{Al}$ with various fluoride salts. (c) Bordoloi, M. Tetrahedron Lett. 1993, 34, 1681. Aliphatic ketones are reduced by $\mathrm{Mg} / \mathrm{CaCl}_{2}$ in water. the previous reports (Table 4), 5,10 In addition to the reactions of carbonyl compounds in $\mathrm{Sm} / 2 \mathrm{M} \mathrm{HCl} / \mathrm{THF}$ (condition (i)), six other conditions have been applied: (ii) $\mathrm{Sm}$ amalgam in $\mathrm{THF}^{10 a}$ (iii) $\mathrm{Sm} / \mathrm{Me}_{3} \mathrm{SiCl}$ with a trace amount of $\mathrm{H}_{2} \mathrm{O}$ in $\mathrm{THF}$, 5 a (iv) $\mathrm{Sm} / \mathrm{I}_{2}$ in $\mathrm{MeOH}$, ${ }^{\mathrm{cc}}$ (v) Sm/ $\mathrm{I}_{2} / \mathrm{Ti}(\mathrm{Oi}-\mathrm{Pr})_{4}$ in $\mathrm{MeOH}$, ${ }^{5 c}$ (vi) Sm/allyl bromide/MeOH, $5 \mathrm{~g}$ and (vii) Sm in THF/HMPA. ${ }^{10 b}$ Benzal dehyde underwent pinacolic coupling reactions exclusively or predominantly in the reaction conditions (i)-(v). We also found that the dimethyl acetal of benzaldehyde reacted with $\mathrm{Sm}$ (3 molar proportions) in $2 \mathrm{M} \mathrm{HCl} / \mathrm{THF}$ (5:1) gave pinacol $2 \mathbf{a}$ in $98 \%$ yield as a mixture of $\mathrm{dl}$ and meso isomers (44:56). The reaction of 2-hydroxybenzal dehyde still gave pinacol $\mathbf{2 k}$ as the major product $(60 \%)$ by using our method, whereas unimolecular reduction occurred preferably by using $\mathrm{Sm} / \mathrm{I}_{2} / \mathrm{Ti}(\mathrm{Oi}-\mathrm{Pr})_{4} / \mathrm{MeOH}$ to give $88 \%$ of benzyl alcohol. ${ }^{5 c}$ The reaction condition (v) using $\mathrm{Sm} / \mathrm{I}_{2} /$ $\mathrm{Ti}(\mathrm{Oi}-\mathrm{Pr})_{4} / \mathrm{MeOH}$ is ineffective for pinacolic couplings of acetophenone or benzophenone. ${ }^{5 c}$ The pinacolic coupling reaction of benzophenone can be accomplished by using Sm activated by $\mathrm{HCl}$, allyl bromide or HMPA. ${ }^{5 g, 10 b}$ Our method using $\mathrm{Sm} / 2 \mathrm{M} \mathrm{HCl} / \mathrm{THF}$ is very efficient for unimolecular reduction of both aliphatic aldehydes and ketones. Use of $\mathrm{Sm} / \mathrm{I}_{2} / \mathrm{MeOH}$ can only reduce aliphatic aldehydes, ${ }^{5 \mathrm{C}}$ whereas aliphatic carbonyls are inert in $\mathrm{Sm} /$ $\mathrm{Me}_{3} \mathrm{SiCl} / \mathrm{H}_{2} \mathrm{O}$

In summary, $\mathrm{Sm}$ with aqueous $\mathrm{HCl}$ is an environmentally benign reducing agent by comparison with other activation methods requiring toxic $\mathrm{Hg}$ or HMPA. Our current method also showed several distinct features comparable or superior to conditions (ii)-(vii). Using of $\mathrm{Sm} / 2 \mathrm{M} \mathrm{HCl} / \mathrm{THF}$, aromatic carbonyls including 4-hydroxybenzaldehyde and benzophenone underwent pinacolic coupling reactions in an efficient manner (Table 2 ). ${ }^{11}$ Treatment of benzaldehyde dimethyl acetal with $\mathrm{Sm} / 2$

(10) (a) Wang, L.; Zhang, Y. Synth. Commun. 1998, 28, 3991. (b) Hou, Z.; Takamine, K.; Aoki, O.; Shiraishi, H.; Fujiwara, Y.; Taniguchi, H. J . Org. Chem. 1988, 53, 6077. Treatment of benzaldehyde with Sm and a catalytic amount of $\mathrm{C}_{2} \mathrm{H}_{5} \mathrm{l}$ affords benzyl benzoate as a consequence of reduction and Tishchenko reaction. See: (c) Yokoo, K.; Mine, N.; Taniguchi, H.; Fujiwara, Y.J . Organomet. Chem. 1985, 279, C19. 
$\mathrm{M} \mathrm{HCl}$ THF also yielded 1,2-diphenyl-1,2-ethanediol via a consecutive hydrolysis and pinacolic coupling reaction. On the other hand, unimolecular reductions of aliphatic aldehydes and ketones were accomplished in $\mathrm{Sm} / 2 \mathrm{M}$ $\mathrm{HCl} / \mathrm{THF}$ (Table 3). 2-Methoxycyclohexanone was cleanly reduced in $\mathrm{Sm} / 2 \mathrm{M} \mathrm{HCl} / \mathrm{THF}$ to give 2-methoxycyclohexanol, although $\mathrm{Sml}_{2}$ is known to cause a reductive cleavage of $\alpha-\mathrm{MeO}$ group. ${ }^{12}$ Reduction of tert-butyl acetoacetate in $\mathrm{Sm} / 2 \mathrm{M} \mathrm{HCl} / \mathrm{THF}$ afforded tert-butyl 3-hydroxybutanoate without attacking the ester group.

\section{Experimental Section}

Representative Procedure for the Reaction of Carbonyl Compounds with Samarium in Aqueous Media. To a

(11) $\mathrm{Sml}_{2}$ or $\mathrm{Ce} / \mathrm{I}_{2}$ in THF fail to conduct the pinacolic coupling reaction of benzophenone. See: (a) Kahn, B.; Rieke, R. D. Chem. Rev. 1988, 88, 733. (b) Furstner, A.; Csuk, R.; Rohrer, C.; Weidmann, H.J . Chem. Soc., Perkin Trans. 1 1988, 1729. (c) Imamoto, T.; Kusumoto, T.; Hatanaka, Y.; Yokoyama, M. Tetrahedron Lett. 1982, 23, 1353. Pinacolic coupling of benzophenone can be achieved by using $\mathrm{Yb} /\left(\mathrm{C}_{6} \mathrm{~F}_{5}\right)_{2}$ Hg in THF. See: (d) Deacon, G. B.; Tuong, T. D. J . Organomet. Chem. 1981, 205, C4.

(12) F or $C_{\alpha}-O$ bond cleavage of $\alpha$-alkoxy-, $\alpha$-acetoxy-, and $\alpha$-hydroxyketones by $\mathrm{Sml}_{2}$, see: (a) I nanaga, J. Heteroatom. Chem. 1990 3, 75. (b) Pratt, D. V.; Hopkins, P. B. Tetrahedron Lett. 1987, 28, 3065. (c) Molander, G. A.; Hahn, G. J . Org. Chem. 1986, 51, 1135. (d) White, J. D.; Somers, T. C. J . Am. Chem. Soc. 1987, 109, 4424. (e) Holton, R. A.; Williams, A. D. J . Org. Chem. 1988, 53, 5981. suspension of 4-bromobenzal dehyde ( $\mathbf{l b}, 185 \mathrm{mg}, 1 \mathrm{mmol}$ ) in 2 $\mathrm{M} \mathrm{HCl} / \mathrm{THF}(5: 1,5 \mathrm{~mL})$ was added Sm ( $450 \mathrm{mg}, 3 \mathrm{mmol}$, freshly abraded from ingot) in several portions over a period of $1 \mathrm{~h}$ at room temperature. Upon addition of Sm powders, the medium turned purple but the color discharged instantly. Evolution of heat and hydrogen gas was obvious. The reaction mixture was continuously stirred without rigorous exclusion of oxygen. Complete consumption of 4-bromobenzal dehyde required $32 \mathrm{~h}$, as shown by TLC analyses. The medium became transparent yellow solution, and no residue of Sm particles remained. The solution was neutralized and extracted with EtOAc/hexane (1: 1). The organic phase was washed with brine, dried $\left(\mathrm{Na}_{2} \mathrm{SO}_{4}\right)$ and concentrated in vacuo. The crude product mixture (176 mg) contained pinacol $\mathbf{d l}-\mathbf{2} \mathbf{b}$, pinacol meso-2b and alcohol $\mathbf{3 b}$ in a ratio of 34:60:6 according to the ${ }^{1} \mathrm{H}$ NMR analysis. Pure pinacols (164 mg, 88\%) were obtained by crystallization from EtOAd hexane (1:9).

The pinacols $\mathbf{2} \mathbf{a}-\mathbf{q}$ and alcohols $\mathbf{3} \mathbf{a}-\mathbf{q}$ and $\mathbf{5 a}-\mathbf{k}$ exhibited their IR, ${ }^{1} \mathrm{H}$ and ${ }^{13} \mathrm{C}$ N MR spectra consistent with those reported in the literature.

Acknowledgment. We thank the National Science Council for financial support. S.T. thanks NSC for a postdoctoral fellowship.

J $0001362 S$ 